\title{
Short communication: lodine concentrations in serum, milk, and tears after feeding Ascophyllum nodosum to dairy cows-A pilot study
}

\author{
U. S. Sorge,${ }^{* 1}$ M. Henriksen, † A. Bastan, $\ddagger$ N. Cremers, $\S$ K. Olsen, $\S$ and B. A. Crooker\# \\ *Department of Veterinary Population Medicine, University of Minnesota, Saint Paul 55108 \\ †Department of Veterinary Clinical Sciences, University of Minnesota, Saint Paul 55108 \\ $\ddagger$ Faculty of Veterinary Medicine, Department of Obstetrics and Gynaecology, Ankara University, Ankara, Turkey \\ §Veterinary Diagnostic Laboratory, University of Minnesota, Saint Paul 55108 \\ \#Department of Animal Science, University of Minnesota, Saint Paul 55108
}

\section{ABSTRACT}

Kelp (Ascophyllum nodosum) is rich in iodine and often fed by organic dairy producers as a mineral supplement to support animal health. A commonly held belief is that kelp supplementation decreases susceptibility to infectious bovine keratoconjunctivitis due to increased iodine concentrations in tears. Whereas serum and milk iodine concentrations are positively correlated and modulated by oral iodine supplementation, nothing is known about the iodine concentration of tears. Therefore, the 3 objectives of this pilot study were to determine (1) the iodine content of tears, milk, and serum of cows after being fed kelp for $30 \mathrm{~d}$; (2) the trace mineral and thyroid status of cows before (d 0$)$ and after being fed kelp for $30 \mathrm{~d}$; and (3) the in vitro growth rate of bacteria in tears (Moraxella bovis) or milk (Staphylococcus aureus, Escherichia coli, Streptococcus uberis) collected from cows fed no kelp (d 0) or kelp (d 30). Cows $(\mathrm{n}=3 /$ treatment) were individually fed $56 \mathrm{~g}$ of kelp per day $(\mathrm{n}=3 /$ treatment $)$ or not $(\mathrm{n}=$ $3 /$ no treatment) for $30 \mathrm{~d}$. Daily feed intake of the TMR was recorded and weekly TMR, kelp, milk, blood and tear samples were collected and analyzed for iodine. The feed samples were pooled and further analyzed for other minerals. On d 0 and 30, liver biopsies and blood samples were collected and analyzed for mineral content and thyroid hormone concentrations, respectively. An inhibition test used milk and tear-soaked plates from kelp-fed cows (d 0 and 30) as well as 1 and $7.5 \%$ iodine as positive and distilled water as negative control. As expected, serum iodine concentrations were positively correlated with milk and tear iodine concentrations. Whereas the iodine concentrations in serum increased significantly in the kelp-fed cows during the 30-d study, milk and tear iodine concentrations increased only numerically in these cows compared with the control

Received December 23, 2015.

Accepted June 11, 2016.

${ }^{1}$ Corresponding author: sorge@umn.edu group. Liver mineral profiles were comparable between groups and generally did not change over the course of the study. Thyroid hormones remained overall within the reference range throughout the trial. Neither milk nor tears from kelp-fed cows inhibited in vitro growth of any of the plated bacteria. In summary, serum iodine concentration was correlated with the iodine concentration in milk and tears and feeding kelp increased only the serum iodine levels of cows in this trial. Bacterial growth was not inhibited in milk and tears of kelp-fed cattle in vitro, and prevention of infectious bovine keratoconjunctivitis would not be based solely on increased iodine concentrations in tears.

Key words: tears, iodine, kelp, Ascophyllum nodosum, infectious bovine keratoconjunctivitis

\section{Short Communication}

Organic producers are using different preventive approaches to support animal health because their treatment options are limited (AMS, 2015). Feed supplementation with kelp (Ascophyllum nodosum), a brown seaweed, as a mineral source is practiced by well over $50 \%$ of organic dairy producers (Antaya et al., 2015; Sorge et al., 2016). Many organic dairy producers believe that feeding kelp will improve the health of their animals because kelp is rich in iodine and other important trace minerals (Antaya et al., 2015). The positive effect of kelp on health is mostly focused on improved udder health, reproduction, and particularly the prevention of infectious bovine keratoconjunctivitis, which is also called pink eye (Olree and Dettloff, 2010; Antaya et al., 2015). In particular, the latter observation is explained by the assumption that an increased concentration of iodine in tears will decrease the growth of Moraxella bovis or Moraxella bovoculi, the causative agents of pink eye. However, although feeding kelp indeed increases the iodine concentration in hair (Olree and Dettloff, 2010) and milk of cows (Antaya et al., 2015), little information is available at present to assess the effect of kelp supplementation on cattle health. The 
only existing long-term study supplemented a different kind of kelp (Macrocystis pyrifera) and the authors were unable to find any "consistent differences which [could] be attributed to the rations fed. [...] The addition of kelp meal to normal rations for dairy heifers showed no particular benefits for growth, breeding efficiency, general health, physical condition, appetite, and size and condition of calves at birth" (Berry and Turk, 1944). To the best of our knowledge, no studies have been conducted to validate the effect of feeding kelp on the incidence of infectious bovine keratoconjunctivitis, let alone to measure the iodine concentration in tears. However, it is well established that iodine is crucial for animal health. Oral iodine supplementation is positively correlated with the iodine concentrations in serum and milk in cows (Schöne et al., 2009) and feeding iodine-rich kelp increases iodine levels in milk (ReyCrespo et al., 2014; Antaya et al., 2015). Therefore, it is probable that the concentration of iodine in serum and tears could also be positively correlated. Increased iodine concentrations in tears may indeed improve the animal's ability to cope with $M$. bovis infections, just as increased iodine levels in the upper respiratory tract contributed to airway antiviral defenses (Derscheid et al., 2014). Therefore, the 3 objectives of this pilot study were to determine (1) the iodine content of tears, milk, and serum of cows after being fed kelp (56 g/d) for $30 \mathrm{~d}$; (2) the trace mineral and thyroid status of cows before (d 0) and after being fed kelp for $30 \mathrm{~d}$; and (3) the in vitro growth rate of bacteria in tears (Moraxella bovis) or milk (Staphylococcus aureus, Escherichia coli, Streptococcus uberis) collected from cows fed no kelp (d 0) or kelp (d 30). We hypothesize that the tear iodine concentration is affected by alimentary iodine uptake and is positively associated with serum and milk iodine concentration. Furthermore, we hypothesize that an increased iodine concentration would decrease the growth rate of Moraxella bovis in tears and that of Staph. aureus, E. coli, and Klebsiella in milk compared with the original iodine concentrations in tears and milk, respectively.

To address objectives 1 and 2, based on the results of Schöne et al. (2009), we expected a change in the serum iodine concentration from 66 to $131 \mu \mathrm{g} / \mathrm{L}$ (SD $\sim 20$ ) over the 30 -d trial. Assuming $80 \%$ power and $95 \%$ confidence, at least 2 cows would be needed to show this difference in serum iodine concentration (objective 2). Therefore, 3 mid to late lactation Holstein Friesian cows of the University of Minnesota's Saint Paul campus dairy were enrolled per treatment to account for potential losses during the study and for potentially lower iodine concentrations in tears. The cows were healthy and had not received kelp or other additional iodine supplementation previously. The Holstein Frie- sian cows were randomly assigned to either the kelp $(\mathrm{n}=3)$ or the negative control group $(\mathrm{n}=3)$. The cows were fed an individually weighed TMR that was the same for all cows (Table 1). The kelp group was additionally fed $56 \mathrm{~g} / \mathrm{d}$ of kelp (Kelp, Thorvin, New Castle, VA) that was manually top dressed and mixed into the TMR at $28 \mathrm{~g}$ in the morning and evening feeding. The $56 \mathrm{~g} / \mathrm{d}$ responded to a recommended $0.5 \%$ of DMI (E. Chandler, Thorvin, personal communication). Each morning, the refusal was weighed to estimate the daily intake of each cow. Furthermore, each week, a small sample of the kelp fed as well as a grab sample of the TMR were collected and frozen. The weekly kelp and TMR samples were combined (separately) for subsequent mineral and iodine analysis.

Blood (10-mL serum Vacutainer, 21-gauge, 1.5-inch needles; BD, Franklin Lakes, NJ,) and tear samples were collected weekly from each cow (d 0, 7, 14, 21, and 30 ). To collect tears, the head of the cow was restrained with a halter, the third eye lid of the cow was prolapsed, and a Weck-Cel sponge (Weck-Cel, Merisol, Houston, TX) was gently held into the medial corner of the cow's eye to absorb approximately $1 \mathrm{~mL}$ of tear fluid per eye in the morning and afternoon after the cows returned from milking. The sponge was placed into a $2.5-\mathrm{mL}$ Eppendorf tube with microfilter and centrifuged at 3,000 $\times g$ for 20 min at $20^{\circ} \mathrm{C}$.

Table 1. Composition of TMR fed to all cows

\begin{tabular}{lr}
\hline Item & \\
\hline Ingredient (\% of DM) & \\
Alfalfa hay & 12.73 \\
Grass hay & 2.73 \\
Corn silage & 33.64 \\
Corn gluten feed & 6.36 \\
Corn grain, ground & 10.91 \\
Cottonseed, fuzzy (with linters) & 5.00 \\
Molasses, liquid & 3.63 \\
Protein mix & 23.64 \\
Energy Booster ${ }^{2}$ & 1.36 \\
Component & \\
DM (\%) & 59.30 \\
CP (\%) & 16.50 \\
NE & 0.81 \\
NE & Mcal/kg) $(M c a l / k g)$ \\
ADF (\%) & 0.52 \\
NDF (\%) & 24.20 \\
Ca (\%) & 33.70 \\
P (\%) & 0.66 \\
Proin & 0.40
\end{tabular}

${ }^{1}$ Protein mix included fine rolled corn $(34.91 \%)$, canola meal (14.07\%), soybean meal, $47 \%$ (12.80), SoyPass (11.31\%; LignoTech, Rothschild, WI), dry distillers grain $(10.69 \%)$, blood meal $(4.28 \%)$, sodium bicarbonate $(3.90 \%)$, calcium carbonate $(3.68 \%)$, Ultramet $(1.90 \%$; Vita Plus Corp., Madison, WI, including liquid MetaSmart, Adisseo, Alpharetta, GA), potassium carbonate $(1.08 \%)$, white salt $(0.92 \%)$, magnesium oxide (0.43\%), and Rumensin (0.03\%; Elanco Animal Health, Greenfield, IN) on a DM basis.

${ }^{2}$ Energy Booster 100 (Milk Specialties, Eden Prairie, MN) is hydrogenated fat. 
Furthermore, on d 0 and 30, duplicate aseptic composite milk samples were also collected. Briefly, all teat ends were disinfected with alcohol swabs. After discarding a squirt of milk, approximately 2 squirts were collected from all 4 teats $(\sim 50 \mathrm{~mL}$ total $)$ in duplicate. In addition to the milk sample, blood samples (10-mL EDTA Vacutainer, BD) and a liver biopsy (Carriquiry et al., 2009) were collected for the analysis of the thyroid hormone profile [total thyroxine (T4), total triiodothyronine (T3), free T4, free T3] and assessment of the trace mineral status of the cows, respectively. All samples were immediately placed on ice, processed within $1 \mathrm{~h}$ of sampling, and frozen at $-20^{\circ} \mathrm{C}$ before being sent to the Diagnostic Center for Population and Animal Health of the Michigan State University for analysis. All samples, except the liver samples, were analyzed for iodine. Furthermore, the laboratory used T4 Monoclonal, Free T4, and Free T3 Solid phase Component System Radioimmunoassays (MP Biomedical Diagnostics Division, Orangeburg, NY) that were incubated at $37^{\circ} \mathrm{C}$ for $2,1.5$, and $2.5 \mathrm{~h}$, respectively. Total T3 was quantified with an in-house charcoal separation RIA based on Refsal et al. (1984). The Institutional Animal Care and Use Committee of the University of Minnesota approved all animal procedures before study initiation.

Objective 3 was addressed by using Kirby Bauer tests (Papich, 2013). Briefly, 50- $\mu \mathrm{L}$ aliquots of tears and milk from all 3 cows fed kelp from d 0 and 30 were placed onto sterile discs that were applied to Mueller Hinton blood agar plates inoculated with Moraxella bovis (ATCC 10900) and field isolates of Strep. uberis, as well as Mueller Hinton plates inoculated with E. coli and Staph. aureus from the Udder Health Laboratory of the University of Minnesota. In addition, disks soaked with $50 \mu \mathrm{L}$ of $1 \%$ iodine, $7.5 \%$ iodine, and sterile water were also placed on the plates as positive and negative controls. The iodine concentrations were selected to represent common iodine concentrations in teat dip (1\%, Dinsmore and Hirst, 2002) as well as iodine concentrations for killing bacteria (Salvi et al., 2006). The plates were incubated at $37^{\circ} \mathrm{C}$ with $\mathrm{CO}_{2}$ and visually assessed for zones of inhibition at 24 and $48 \mathrm{~h}$.

The data were analyzed in SAS 9.4 (SAS Institute Inc., Cary, NC). The observations were reported as mean \pm standard error of the mean by group. The association between serum, milk, and tear iodine concentrations was assessed with Spearman correlations. The serum, milk, and iodine concentrations between the kelp-fed and control groups were initially compared with a Student $t$-test, including Satterthwaite correction for unequal variances. Furthermore, least squares means were calculated for tear, serum, and milk iodine concentrations at d 30 while accounting for group (kelp vs. control) and initial (d 0) tear, serum, or milk iodine concentration as fixed effects (PROC MIXED), respectively. A paired $t$-test (PROC TTEST) was used to assess the change in liver mineral, serum, milk, and tear iodine as well as thyroid hormone concentrations of cows between d 0 and 30 to account for the dependency of the data.

At the start of the study, cows of the control and kelp-fed group weighed $631 \pm 23 \mathrm{~kg}$ (mean $\pm \mathrm{SEM}$ ) and $690 \pm 43 \mathrm{~kg}$, respectively $(P=0.31)$. The unadjusted daily DMI was $26.6 \pm 0.88$ and $28.8 \pm 0.39 \mathrm{~kg} / \mathrm{d}$ and the mean dietary iodine intake was $99.4 \pm 1.91 \mathrm{mg}$ and $62.5 \pm 0.85 \mathrm{mg} / \mathrm{d}$ by kelp-fed and control cows, respectively $(P<0.01)$. No difference was found between the daily weigh back (i.e., left over feed) between kelp-fed $(4.6 \% \pm 4.6 \%)$ and control cows $(5.5 \pm 5.1 \%$, $P=0.10)$.

An unexpected observation was that already the baseline serum iodine concentration was above the reference range of 50 to $120 \mathrm{ng} / \mathrm{mL}$ (minimum: $231 \mathrm{ng} /$ $\mathrm{mL}$ ) and was in the range observed for cows with hyperplastic goiter (Ong et al., 2014). The TMR contained inexplicably high iodine concentrations that were well above NRC (2001) suggestions of $<0.6 \mathrm{mg} / \mathrm{kg}$ (Table 2 ), although none of the feed components included additional iodine. However, as expected, the serum iodine concentrations were correlated with tear $(\mathrm{r}=0.58, P<$ $0.01)$ as well as milk iodine levels $(\mathrm{r}=0.54, P=0.06$, tendency) and increased after kelp supplementation when accounting for the baseline (d 0) serum iodine concentrations (Table 3). However, even when using all available samples, tear and milk iodine concentrations were not correlated $(\mathrm{r}=0.07, P=0.81)$. Furthermore, whereas the iodine concentration in milk $(P=0.38)$ and tears $(P=0.17)$ increased only numerically over time within groups, the milk iodine concentration on d 30 was slightly higher in the kelp-fed than control group $(P=0.05)$. The observed lack of a statistically significant differences over time within groups could be a result of the lack of power due to the unexpectedly high baseline iodine values, which decreased the expected difference between treatments. In addition, the tear production (total volume was not measured) may have differed between cows and days and may have affected the results despite the standardization of the tear collection.

Although kelp is primarily used as an iodine supplement, it is also used as a supplement for other minerals (Sorge et al., 2016). However, liver mineral concentrations did not change in either group over time (Table 3 , $P>0.25)$. The changes in cobalt and zinc are biologically negligible. Overall, total T4 (40.0 \pm 1.0 to $45.7 \pm$ $2.8 \mathrm{nmol} / \mathrm{L})$, total T3 $(1.8 \pm 0.1$ to $2.1 \pm 0.1 \mathrm{nmol} / \mathrm{L})$, free $\mathrm{T} 4(10.3 \pm 0.3$ to $12.7 \pm 0.3 \mathrm{pmol} / \mathrm{L})$, and free T3 
Table 2. Mineral composition of Ascophyllum nodosum and the TMR on a DM basis

\begin{tabular}{lcc}
\hline Item & A. nodosum & TMR \\
\hline Iodine $(\mu \mathrm{g} / \mathrm{g})$ & 743.65 & 2.17 \\
Minerals $(\mathrm{mg} / \mathrm{kg})$ & & \\
Sodium & 42,340 & 5,656 \\
Sulfur & 28,169 & 2,877 \\
Potassium & 28,007 & 13,208 \\
Calcium & 13,137 & 7,741 \\
Magnesium & 8,255 & 3,708 \\
Phosphorus & 1,637 & 4,007 \\
Iron & 204 & 395 \\
Boron & 108.9 & 10.6 \\
Aluminum & 75.6 & 257 \\
Arsenic & 28.3 & $<2.5$ \\
Manganese & 15.6 & 85.8 \\
Barium & 4.7 & 7 \\
Copper & 1.7 & 18.6 \\
Cobalt & 1.45 & 1.3 \\
Cadmium & 0.9 & $<0.3$ \\
Thallium & $<12.5$ & $<12.5$ \\
Selenium & $<10.0$ & $<10.0$ \\
Mercury & $<10.0$ & $<10.0$ \\
Molybdenum & $<1.0$ & $<1.0$ \\
Lead & $<2.5$ & $<2.5$ \\
Chromium & $<1.0$ & $<1.0$ \\
Antimony & $<5.0$ & $<5.0$ \\
\hline
\end{tabular}

$(3.7 \pm 0.2$ to $5.0 \pm 0.6 \mathrm{pmol} / \mathrm{L})$ serum concentrations did not change over the course of the experiment in the kelp-fed group $(P>0.05)$. This is similar to the observations by Antaya et al. (2015) who also did not find changes in the thyroid hormones after supplementation with kelp. However, although the concentrations were generally within the normal range for cattle (Kafi et al., 2012), the free T3 was above the reference range (2.0-3.0 pmol/L) already at the first sampling and may be particularly influenced by the nutritional iodine intake (Ong et al., 2014). Whether this had clinical implications is not clear because we did not specifically assess the thyroid glands.

Although a previous study had shown some antibacterial activities of Ascophyllum nodosum extracts in vitro (Vacca and Walsh, 1954), milk and tears from study cows did not prevent the in vitro growth of any of the tested bacteria, including Moraxella bovis, regardless of their iodine levels or which group they were from. In contrast, 1 and $7.5 \%$ iodine positive controls did show inhibition of bacterial growth. Therefore, the hypothesis that the iodine concentration of tears has a direct effect on the growth of, for example, Moraxella bovis could not be confirmed, but it remains unclear how or if the previously demonstrated antibacterial properties (Vacca and Walsh, 1954) translate to kelp fed to and digested by ruminants. Siddiqui (1993) speculated that inorganic iodine by itself may decrease bacterial growth or could improve immune function. Indeed, studies have shown that iodine supplementation increased the iodide concentration in the upper respiratory tract (Fischer et al., 2011; Derscheid et al., 2014) and decreased the severity of respiratory syncytial virus disease in lambs (Derscheid et al., 2014) by improving the immune function (Fischer et al., 2011; Derscheid et al., 2014). Similarly, supplementation with iodine was associated with

Table 3. Serum, milk, and tear iodine and liver mineral concentrations (mean \pm SEM) of kelp- and control-fed cows at the beginning (d 0) and end of the experiment (d 30)

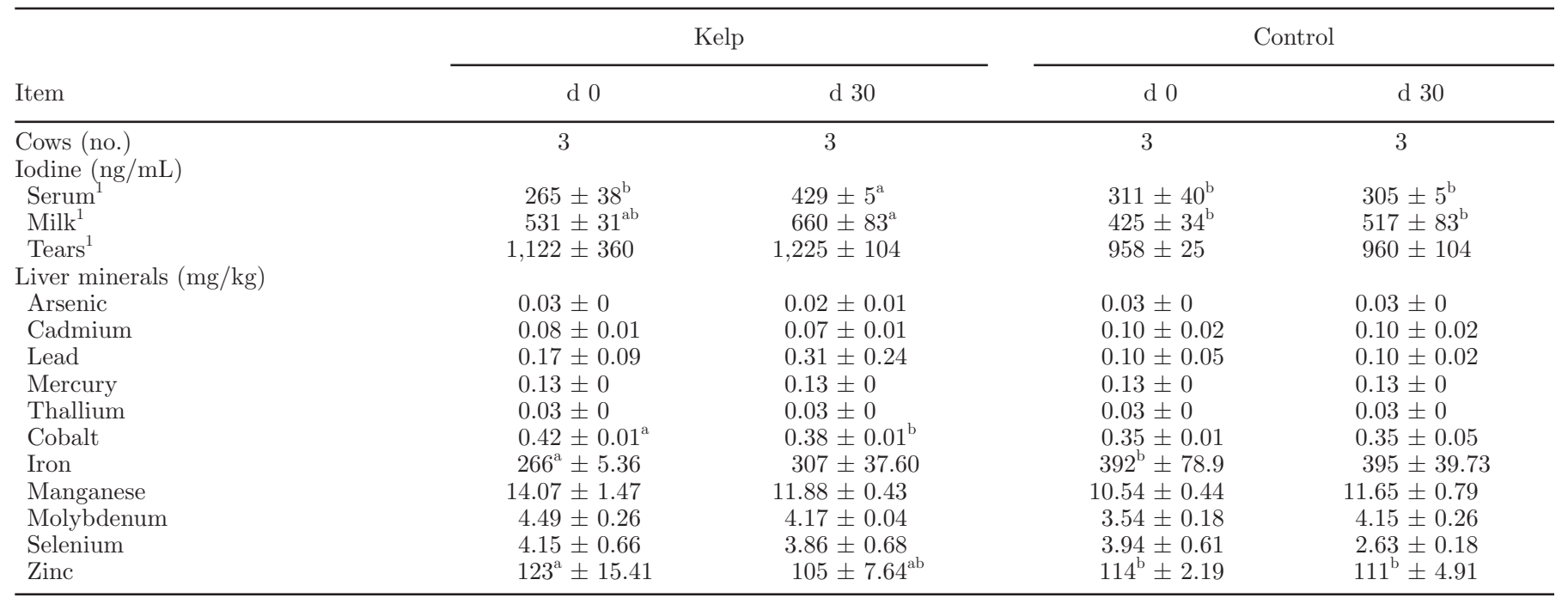

${ }_{\mathrm{a}, \mathrm{b}}$ Different superscripts in a row indicated statistical differences based on a Student- $t$-test between groups on $\mathrm{d} 0$ and 30 and a paired $t$-test within kelp-fed and control cows over time.

${ }^{1}$ The averages at d 30 are LSM based on a linear regression including group and iodine concentration (serum, milk, tears, respectively) at d 0 as fixed effects. 
a decreased incidence of foot rot, a bacterial disease, in feedlot cattle (Berg et al., 1984; Maas et al., 1984). Therefore, one could speculate that iodine from kelp could potentially be supportive of the immune system against infectious bacteria. However, in our study the tears had been centrifuged and frozen and so a potential effect of increased iodine levels through the local immune system could not be assessed.

In summary, serum iodine concentration was correlated with the iodine concentration in milk and tears. However, the feeding of kelp only increased the iodine levels in serum of cows in this study and the iodine concentrations in milk and tears changed only numerically and were not associated with an inhibition of bacterial growth in vitro. Therefore, a prevention of infectious bovine keratoconjunctivitis would probably not be based solely on increased iodine concentrations in tears.

\section{ACKNOWLEDGMENTS}

We thank Nathanial McDonald, Wyatt Smith, and Angel M. Rosales Gallardo (Dept. of Animal Science, University of Minnesota, St. Paul) for their help during data collection.

\section{REFERENCES}

AMS. 2015. National Organic Program. Accessed July 1, 2016. http:// www.ecfr.gov/cgi-bin/text-idx?c=ecfr\&sid=3f34f4c22f9aa8e6d986 4cc2683cea02\&tpl=/ecfrbrowse/Title07/7cfr205_main_02.tpl.

Antaya, N. T., K. J. Soder, J. Kraft, N. L. Whitehouse, N. E. Guindon, P. S. Erickson, A. B. Conroy, and A. F. Brio. 2015. Incremental amounts of Ascophyllum nodosum meal do not improve animal performance but do increase milk iodine output in early lactation dairy cows fed high-forage diets. J. Dairy Sci. 98:1991-2004.

Berg, J. N., J. P. Maas, J. A. Paterson, G. F. Krause, and L. E. Davis. 1984. Efficacy of ethylenediamine dihydriodide as an agent to prevent experimentally induced bovine foot rot. Am. J. Vet. Res. 45:1073-1078.

Berry, M. H., and K. L. Turk. 1944. The value of kelp meal in rations for dairy cattle. J. Dairy Sci. 27:861-866.

Carriquiry, M., W. J. Weber, S. C. Fahrenkrug, and B. A. Crooker. 2009. Hepatic gene expression in multiparous Holstein cows treated with bovine somatotropin and fed n-3 fatty acids in early lactation. J. Dairy Sci. 92:4889-4900.

Derscheid, R. J., A. van Geelen, A. R. Berkebile, J. M. Gallup, S. J. Hostetter, B. Banfi, P. B. McCray Jr., and M. R. Ackermann.
2014. Increased concentration of iodide in airway secretions is associated with reduced respiratory syncytial virus disease severity. Am. J. Respir. Cell Mol. Biol. 50:389-397.

Dinsmore, P., and H. Hirst. 2002. What about this new teat dip? Accessed Feb. 4, 2016. https://www.cvmbs.colostate.edu/ilm/ proinfo/cdn/2002/Teat\%20DipMay02.pdf.

Fischer, A. J., N. J. Lennemann, S. Krishnamurthy, P. Pocza, L. Durairaj, J. L. Launspach, B. A. Rhein, C. Wohlford-Lenane, D. Lorentzen, and B. Banfi. 2011. Enhancement of respiratory mucosal antiviral defenses by the oxidation of iodide. Am. J. Respir. Cell Mol. Biol. 45:874-881.

Kafi, M., A. Tamadon, M. Saeb, A. Mirzaei, and M. Ansari-Lari. 2012. Relationships between thyroid hormones and serum energy metabolites with different patterns of postpartum luteal activity in high producing dairy cows. Animal 6:1253-1260.

Maas, J., L. E. Davis, C. Hempstead, J. N. Berg, and K. A. Hoffman. 1984. Efficacy of ethylenediamine dihydriodide in the prevention of naturally occurring foot rot in cattle. Am. J. Vet. Res. 45:2347-2350

NRC. 2001. Nutrient Requirements of Dairy Cattle. 7th ed. National Academy of Sciences, Washington, DC.

Olree, R., and P. Dettloff. 2010. Kelp and dairy cattle pilot study. Accessed Apr. 30, 2014. http://grassworks.org/?300604/conf.Orlee. Kelp\%20Pilot\%20Study\%20_1_.pdf.

Ong, C. B., T. H. Herdt, and S. D. Fitzgerald. 2014. Hyperplastic goiter in two adult dairy cows. J. Vet. Diagn. Invest. 26:810-814.

Papich, M. D. 2013. VET01-A4: Performance Standards for Antimicrobial Disk and Dilution Susceptibility Tests for Bacteria Isolated From Animals; Approved Standard, 4th ed. Clinical and Laboratory Standards Institute, Wayne, PA.

Refsal, K. R., R. F. Nachreiner, and C. R. Anderson. 1984. Relationship of season, herd, lactation, age, and pregnancy with serum thyroxine and triiodothyronine in Holstein cows. Domest. Anim. Endocrinol. 1:225-234

Rey-Crespo, F., M. López-Alonso, and M. Miranda. 2014. The use of seaweed from the Galician coast as a mineral supplement in organic dairy cattle. Animal 8:580-586.

Salvi, M., C. Chelo, F. Caputo, M. Conte, C. Fontana, G. Peddis, and C. Velluti. 2006. Are surgical scrubbing and pre-operative disinfection of the skin in orthopaedic surgery reliable? Knee Surg. Sports Traumatol. Arthrosc. 14:27-31.

Schöne, F., M. Leiterer, P. Lebzien, D. Bemmann, M. Spolders, and M. Flachowsky. 2009. Iodine concentration of milk in a dose-response study with dairy cows and implications for consumer iodine intake. J. Trace Elem. Med. Biol. 23:84-92.

Siddiqui, M. M. 1993. Effects of organic and inorganic iodine supplementation on the performance and immune response of feedlot cattle. PhD Thesis. Department of Animal Science, Texas Tech University, Lubbock.

Sorge, U. S., R. Moon, L. J. Wolff, L. Michels, S. Schroth, D. F. Kelton, and B. Heins. 2016. Management practices on organic and conventional dairy herds in Minnesota. J. Dairy Sci. 99:3183-3192.

Vacca, D. D., and R. A. Walsh. 1954. The antibacterial activity of an extract obtained from Ascophyllum nodosum. J. Am. Pharm. Assoc. $43: 24-26$ 